\title{
AN INVESTIGATION OF THE RELATIONSHIP BETWEEN DIGITAL GAME ADDICTION, GENDER AND REGULAR SPORT PARTICIPATION
}

\author{
NURULLAH EMIR EKINCI \\ UMIT DOGAN USTUN \\ OMER OZER \\ Dumlupinar University School of Physical Education and Sport, \\ Kutahya/Turkey. \\ E-mail address: ekinciemir@gmail.com
}

\begin{abstract}
This study aims to investigate digital game addiction of high school students according to gender and regular sport participation. For this 398 high school students who were randomly chosen voluntarily participated in the study. In addition to personal information from the Turkish version of Lemmens and colleagues'a game addiction scale was used as a data gathering tool. The Turkish adaptation of the scale was done by Aylin Yalcin Irmak and Semra Erdogan in 2015. The Turkish version of the scale consists of one factor and seven items anchored with a five Likert type scale. In the evaluation of the data linear regression was used. The findings of this study revealed that there was a positive relationship between gender and digital game addiction.
\end{abstract}

Key words: Digital game addiction, gender, regular sport participation

\section{INTRODUCTION}

The games that adolescents and young people used to play in the play grounds and on the streets have been replaced in recent years with digital games played in front of the computer on the internet or in game arcades. This changing culture has particularly brought up the concept of "digital game addiction" which is a condition that stems from the steadily growing passion for digital games and their excessive and uncontrolled usage among adolescents and young people. In the literature game addiction has been described as an impulse control disorder characterized by symptoms such as "the inability to control the time spent on game-playing", "a loss of interest in other activities", "continuing to play despite the adverse effects" and "feeling psychologically deprived when not being able to play" (Yalcin Irmak, \& Erdogan, 2015a, 2015b). 
In order to understand digital game addiction we need to go back at the beginning of digital games.The history of digital games was dominated by two key developments: the first is the rapid increase of popularity and the latter is dynamic technological evolution and diversification (Klimmt, 2009, p. 23).As an example for rapid increase of popularity, in 1962 when Massachusetts Institute of Technology student Steve Russell created Space war -the first interactive computer game- it rune on million-dollar Digital PDP-1 mainframe (Friedman, 1995, p.73).

An addiction to digital games can cause a tremendous amount of consequences to the gamer. In one of the most dramatic stories of online gaming addiction, in 2005, a 28-year-old South Korean man died not by committing suicide, but after playing the game Starcraft at an Internet cafe for 50 hours straight off. By all reports, the man had not slept properly and had eaten very little in that time. While no autopsy was performed, he was believed to have died from heart failure stemming from exhaustion (Young, 2009, p. 355).

Studies show that game addiction may lead to changes in personality or in behavior. According to the study of Mark D. Griffiths and Imogen Dancaster (1995) about the "effect of a type of personality on physiological arousal while playing computer games" they reported systematic measurement of heart rate significantly increased during the game, especially in the case of winning the game or beating one's personal high score is probably equivalent to winning Money in gambling (Griffiths, \& Dancaster 1995, p.543). A study conducted with Korean High School students indicated that students who report excessive internet use are characterized by irritability, aggressiveness and impulsivity (Wo, 2003, p.1135).

Game addiction is a worldwide phenomenon in every aspect. For example digital games have become a serious public health concern in China. About 10 percent of China's more than 30 million Internet gamers were said to be addicted (Young, 2009). And although Turkey started to become familiar with digital games together with color TV sets, VCRs and similar electronic goods since 1983 (when government accepted free market policies and only a lucky minority could afford to buy first game consoles or 8 bit computers) (Yilmaz, \& Cagiltay 2005) today every person can easily buy and spend time on digital games etc.

While having both negative and positive aspects the thoughts on digital games lead to change. According to Leo Sang-Min Whang and Geun-Young Chang (2004) by digital games, players have the power to talk online, make friends and conduct transactions involving real or virtual assets. The entertaining, interactive and real-time online games have become "killer applications" on the Internet and these are the primary reasons that some teenagers spend hours every day playing these games (Whang, \& Chang 2004, p. 592). Also for example in Turkey digital games are accepted as a sport in 2011 by their the incorporation by the Ministry of Youth and Sports (https://tr.wikipedia.org). Because of its being a worldwide phenomenon, digital game 
addiction increased attention of researchers from its early stages up to today. For example in a study carried out by Shotton (1999) about the "old" generation of video games, he concluded that although a small number of people were in danger of becoming dependent on digital games at that time, this was a harmless dependence. However, in the 1990s with the construction of video games with realistic graphics and their requirement for complex skills, this lead to psychological dependence and thus more harmful addictive behaviour (Phillips, Rolls, Rouse, \& Griffiths 1995, p. 687). And because of emerging as one of the most popular forms of mass mediated entertainment and edutainment worldwide, primarily among adolescents (12-17) and young adults (18-22) much of the research has focused on potential social problems related to video game use such as the effects of violent games on aggression (Anderson and Bushman, 2000, p. 353) or game addiction (Fisher, 1994, p. 545). In this study we have tried to explore the possible relationship between digital game addiction gender and regular sport participation of high school students.

\section{METHOD}

Study Design: In the study a cross-sectional method was used as study design and according to Chris Gratton and Ian Jones (2010) this method is perhaps the most commonly used method in social and sport based studies. According to this method the data obtained from a sampling group relationship is identified and generalized back to the population.

Sampling Group: A total of 398 randomly chosen high school students from several schools of Kutahya city center - a city in the west part of Turkey with the population of 325.000- voluntarily participated in the study. But after outliers were analyzed answers of 6 students were eliminated. So finally the sampling group was consisted of 392 high school students [(\%44.1, N=173) female, $(\% 55.9, \mathrm{~N}=219)$ male; $(\% 65.6, \mathrm{~N}=257)$ do regular sport $(\% 34.4, \mathrm{~N}=135)$ not].

Data Collection Tool: In the present study a Turkish version of Lemmens and colleagues' (2009) game addiction scale was used. The Turkish adaptation of the scale was done by Irmak and Erdogan in 2015. The DGAS-7 is a 5-item Likert type, single-dimension scale made up of 7 questions.The Content Validity Index for the DGAS-7 was 0.92, Cronbach's alpha coefficient was 0.72 and item-total correlation ranged between 0.52 and 0.76 (Yalçın Irmak \&Erdoğan 2015b).

Data Analyses: In the evaluation of data first missing value and outlier analyses were made and 6 participants'answers were eliminated. Also skewness and kurtosis values were evaluated and no skewness or kurtosis issues were found. Than reliability of the scale was assessed via Cronbach's alpha method and Cronbach's alpha calculated as .753. Lastly the linear regression method was used as hypothesis test. 


\section{FINDINGS}

Table 1. The distribution of the answers of the scale.

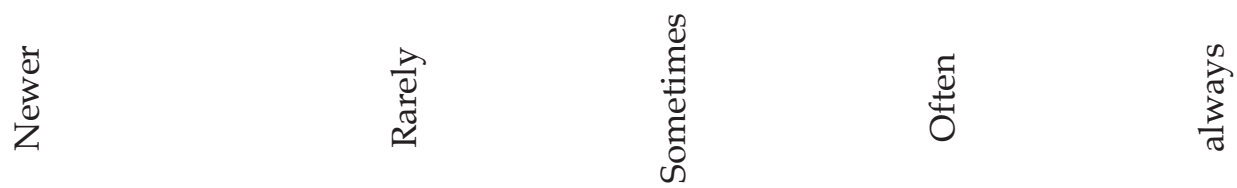

\begin{tabular}{ccccccccccc}
\hline & $\mathrm{F}$ & $\%$ & $\mathrm{f}$ & $\%$ & $\mathrm{f}$ & $\%$ & $\mathrm{f}$ & $\%$ & $\mathrm{f}$ & $\%$ \\
\hline 1 & 180 & 45,9 & 94 & 24 & 83 & 21,2 & 18 & 4,6 & 17 & 4,3 \\
\hline 2 & 137 & 34,9 & 123 & 31,4 & 102 & 26 & 21 & 5,4 & 9 & 2,3 \\
\hline 3 & 134 & 34,2 & 104 & 26,5 & 96 & 24,5 & 43 & 11 & 15 & 3,8 \\
\hline 4 & 171 & 43,6 & 90 & 23 & 76 & 19,4 & 33 & 8,4 & 22 & 5,6 \\
\hline 5 & 207 & 52,8 & 78 & 19,9 & 68 & 17,3 & 21 & 5,4 & 18 & 4,6 \\
\hline 6 & 230 & 58,7 & 87 & 22,2 & 54 & 13,8 & 18 & 4,6 & 3 & 0,8 \\
\hline 7 & 287 & 73,2 & 53 & 13,5 & 40 & 10,2 & 9 & 2,3 & 3 & 0,8 \\
\hline
\end{tabular}

Source: Own chart

Table 2. Regression analyze results

\section{Model Summary}

\begin{tabular}{cccc}
\hline $\mathrm{R}$ & $\mathrm{R}$ Square & Adjusted R Square & Std. Error of the Estimate \\
\hline $.428^{\mathrm{a}}$ & .183 & .179 & 4.00265 \\
\hline
\end{tabular}

a. Predictors: (Constant), regular sport participation, gender

Source: Own chart

Table 3.

\begin{tabular}{cccccc}
\hline \multicolumn{7}{c}{ Anova $^{\text {a }}$} \\
\hline Sum of Squares & df & Mean Square & F & p. \\
\hline Regression & 1396.802 & 2 & 698.401 & 43.592 & $.000^{b}$ \\
\hline Residual & 6232.260 & 389 & 16.021 & \\
\hline Total & 7629.061 & 391 & & \\
\hline a. Dependent Variable: game addiction \\
\hline b. Predictors: (Constant), regular sport participation, gender
\end{tabular}

Source: Own chart

Table 4.

\begin{tabular}{|c|c|c|c|c|c|}
\hline \multicolumn{6}{|c|}{ Coefficients $^{a}$} \\
\hline & Uns & $\begin{array}{l}\text { rdized } \\
\text { ents }\end{array}$ & $\begin{array}{c}\text { Standardized } \\
\text { Coefficients }\end{array}$ & & \\
\hline & $\mathrm{B}$ & Std. Error & Beta & $\mathrm{t}$ & $\mathrm{P}$ \\
\hline (Constant) & 7.720 & .913 & & 8.453 & .000 \\
\hline Gender & 3.785 & .408 & .426 & 9.266 & .000 \\
\hline $\begin{array}{l}\text { Regular sport } \\
\text { participation }\end{array}$ & -.172 & .427 & -.019 & -.404 & .686 \\
\hline
\end{tabular}

Source: Own chart 
Note: According to analysed result there was a significant relationship between participants' gender and game addiction $(R=.426, p<.001)$ but the relationship between doing regular sport and game addiction was found to be insignificant $(\mathrm{R}=-.019 ; \mathrm{p}>.05)$. Also analysis results revealed that game addiction according to gender explains $18 \%$ of total variance $\left(\mathrm{R}^{2}=.183\right)$, and when $t$ values were considered it can be said that gender is a predictor of digital game addiction $(\mathrm{t}=9.266 ; \mathrm{p}<.001)$.

\section{RESULT AND CONCLUSION}

This paper has tried to examine the relationship between game addiction, gender and regular sport participation. Firstly analyzed results showed that the relationship between gender and game addiction was found to be significant $(\mathrm{R}=.426, \mathrm{p}<.001)$. When we examine the literature, studies show that male students dedicate more time than females to playing digital games (Bonanno, \& Kommers 2005). For example in the study of Phillips et al. (1995) males were 1-4 times more likely to admit to playing than females. In their study Bonanno and Kommers (2005) they tried to explain this situation as: "the gender difference in time dedicated to game play can be attributed to the fact that boys find digital games much more attractive and conducive to their natural cognitive processing". But according to study of Kim et al. (2008) about the online game addiction and some personality traits there weren't any significant differences between males and females game addiction.

Secondly relationship between regular sport participation and game addiction was found to be insignificant $(\mathrm{R}=-.019 ; \mathrm{p}>.05)$. So we refuted our hypothesis.

\section{LIMITATIONS AND FUTURE STUDIES}

Although this study had some limitations such as the number of participants, we believe it may enlighten similar future studies. The results of this study revealed a relationship between gender and digital game addiction but no relationship according to regular sport participation. According to Nick Yee (2006) as the addiction progress grows, gamers become less interested in hobbies or activities that they used to enjoy and become more fascinated with living inside the game. So future studies may focus on the time spend on both digital games and sport and may focus on different sampling groups. 


\section{REFERENCES}

[1] Anderson, C. A., \& Bushman, B. J. (2001). Effects of violent video games on aggressive behavior, aggressive cognition, aggressive affect, physiological arousal and prosocial behavior: a meta-analytic review of the scientific literature. Psychological Science, 12, 353-359.

[2] Bonannoa, P., \& Kommers, P. A. M. (2005). Gender differences and styles in the use of digital games. Educational Psychology, 25 (1), 13-41.

[3] Fisher, S. (1994). Identifying video game addiction in children and adolescent. Addictive Behaviors, $19,545-553$.

[4] Friedman, T. (1995). Making Sense of Software: Computer Games and Interactive Textuality, In: S.G. Jones (Ed.), Cybersociety: Computer-Mediated Communication and Community (pp. 73-89). London, Sage Publications.

[5] Gratton, C., \& Jones, I. (2010). Research Methods For Sport Studies, $2^{\text {nd }}$ Edition, London: Routladge.

[6] Griffiths, M.D., \& Dancaster, I. (1995). The effect of type a personality on physiological arousal while playing computer games. Addictive Behaviors, 20 (4), 543-548.

[7] Kim, E.J., Namkoong, K., Ku, T. \& Kim, S.J. (2008). The relationship between online game addiction and aggression, self-control and narcissistic personality traits, science direct. European psychiatry, 23, 212-218.

[8] Klimmt, C. (2009). Key dimensions of contemporary video game literacy: towards a normative model of the competent digital gamer, eludamos. Journal For Computer Game Culture, 3 (1), 23-31.

[9] Lemmens, J. S.,Valkenburg, P. M., \& Peter, J. (2009). Development and validation of a game addiction scale for adolescents. Media Psychology, 12 (1), 77-95.

[10] Oh, W. (2003). Factors Influencing internet addiction tendency among middle school students in gyeong-buk area. Taehan Kanho Hakhoe Chi, 33, 1135-1144.

[11] Phillips, C.A., Rolls S., Rouse A., \& Griffiths M. D. (1995). Home video game playing in schoolchildren: a study of incidence and patterns of play. Journal of Adolescence, 18, 687-691.

[12] Whang, L.S., \& Chang G. (2004). Lifestyles of virtual world residents: living in the on line game "lineage".Cyberpsychology, Behavior, and Social Networking, 7, 592-600.

[13] Yalçin Irmak, A., \& Erdoğan, S. (2015). Ergen ve genç erişkinlerde dijital oyun bağımlılı̆̆ı: güncel bir bakış. Retrieved from http://www.turkpsikiyatri. com/Data/UnpublishedArticles/20y2to.pdf

[14] Yalçın Irmak, A., \& Erdoğan, S. (2015b). Validity and reliability of the Turkish version of the digital game addiction scale. Anatolian Journal of Psychiatry, Doi: 10.5455/Apd.170337.

[15] Yee, N. (2006). The labor of fun: how video games blur the boundaries of work and play. Games And Culture, 1, 68-71

[16] Yilmaz, E., \& Cagiltay, K. (2005). History of digital games in turkey, proceedings of digra 2005 conference: Changing Views - Worlds In Play.

[17] Young, K. (2009). Understanding online gaming addiction and treatment issues for adolescents. The American Journal Of Family Therapy, 37, 355-372.

[18] Wikipedia, (2016; July 20). Dijital Oyunlar. Retrieved from https://Tr.Wikipedia.Org/Wiki/ Türkiye_Dijital_Oyunlar_Federasyonu. 